\title{
Design of Microstrip Patch Antenna using Defected Ground Structure for WLAN Band
}

\author{
Sukhdeep Kaur \\ Student \\ Department of Electronics and communication \\ Lovely Professional University, Phagwara, India
}

\author{
Neha Ahuja \\ Assistant Professor \\ Department of Electronics and communication \\ Lovely Professional University, Phagwara, India
}

\begin{abstract}
This paper presents the Microstrip patch antenna for WLAN applications. The microstrip antenna has a planar geometry and it consists of a defected ground, a feed, a substrate, a patch and a defected ground structure. The design with DGS has been analysed and the simulation using the CST Microwave Studio commercial software for WLAN band at $5.20 \mathrm{GHz}$ frequency with corresponding bandwidth of 304 $\mathrm{MHz}$ to optimize antenna's properties. Results show that the designed antenna has favourable characteristics at this frequency.
\end{abstract}

\section{General Terms}

Microstrip line feed and Microstrip Antenna.

\section{Keywords}

DGS, WLAN Communication Standard, CST Microwave Studio.

\section{INTRODUCTION}

The microstrip patch antenna is one of the most useful antennas for low cost and compact design for RF applications and wireless systems. In wireless mobile communication and satellite applications, microstrip antenna has attracted much interest because of their small size, low cost on mass production, light weight, low profile and easy integration with the other components [1-2]. The major drawback of microstrip patch antenna is the narrow bandwidth. There are many approaches that can be implemented in order to enhance the bandwidth of the microstrip patch antenna. An individual microstrip patch antenna has a typical gain of about $6 \mathrm{~dB}$. Several approaches have been used to enhance the bandwidth by perturbing the higher order mode by interpolating surface modification into patch geometry. Gain enhancement by cutting rectangular hole on another inserted layer. A symmetrical hole on the inserted layer is used which is the major frequency in modern wireless communication era [3]. But the most unique technique to reduce the size of patch is to defect the ground. While comparing the antenna with the defected ground structure and the antenna without the defected ground, the antenna having defected ground structure reduces the size of antenna [4]. The percentage of reduction of size depends upon the ground area that is defected. Defected Ground Structure disturbs the shielded current distribution that depends on the dimension and shape of the defect. The current flow and the input impedance of antenna are then influenced by the disturbance at shielded current distribution due to the DGS structure. The DGS structure can also use to control the excitation and the electromagnetic waves propagating through the substrate layer [5]. In this paper, microstrip antenna for WLAN applications at frequency 5.20 $\mathrm{GHz}(5.055 \mathrm{GHz}$ to $5.360 \mathrm{GHz})$ is designed and simulated using the CST Microwave Studio.

\section{GEOMETRY OF MICROSTRIP PATCH ANTENNA}

In this antenna, the substrate has the thickness of $h=1.524 \mathrm{~mm}$ and a relative permittivity $\varepsilon_{\mathrm{r}}=4.4$. The Length and Width of patch are $11.84 \mathrm{~mm}$ and $19.06 \mathrm{~mm}$ respectively and length and width of substrate are $22.64 \mathrm{~mm}$ and $26.96 \mathrm{~mm}$ respectively. The structure used for ground is defected ground structure. The main concept behind the proposed antenna is to implement DGS structure to enhance the bandwidth of the designed antenna. Microstrip patch antenna can be fed by different types of methods such as microstrip line feed, aperture coupling, electromagnetic coupling, coaxial probe feed and coplanar waveguide (CPW). The DGS consists of the two rectangular areas and one connecting slot in the ground plane [6] as shown in figure 1.

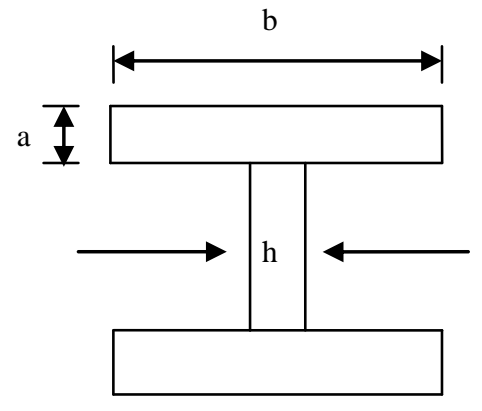

Figure 1: DGS

In this work, microstrip line (50 ohm) feed has been used. In this design we have used a defected ground structure which gives the very good resonance. Antenna is designed for the resonating frequency of $5.20 \mathrm{GHz}$ and is analyzed by using the CST Microwave Studio software. For the designing of rectangular microstrip patch antenna, the following relationships are used to calculate the dimensions of the rectangular microstrip patch antenna [7-8].

$\varepsilon_{\text {reff }}=\frac{\varepsilon_{r}+1}{2}+\frac{\varepsilon_{r}-1}{2}\left[1+12 \frac{h}{W}\right]^{-\frac{1}{2}}$

The effective length is given by

$$
L_{e f f}=\frac{c}{2 f_{o} \sqrt{\varepsilon_{\text {reff }}}}
$$

The length extension $(\Delta \mathrm{L})$ is given by 


$$
\frac{\Delta L}{h}=0.412 \frac{\left(\varepsilon_{\text {reff }}+0.3\right)\left(\frac{W}{h}+0.264\right)}{\left(\varepsilon_{\text {reff }}-0.258\right)\left(\frac{W}{h}+0.8\right)}
$$

The actual length $(\mathrm{L})$ of patch is obtained by:

$L=L_{\text {eff }}-2 \Delta L$

$$
f_{r}=\frac{1}{2 L \sqrt{\varepsilon_{r} \varepsilon_{o} \mu_{0}}}=\frac{v_{o}}{2 L \sqrt{\varepsilon_{r}}}
$$

The width of the patch element $(\mathrm{W})$ is given by:

$$
W=\frac{1}{2 f_{r} \sqrt{\mu_{0} \varepsilon_{o}}} \sqrt{\frac{2}{\varepsilon_{r}+1}}
$$

$$
L_{g}=6 h+L
$$

$$
W_{g}=6 h+W
$$

Where,

$\mathrm{h}=$ substrate thickness

$\mathrm{L}=$ length of patch

$\mathrm{L}_{\text {eff }}=$ effective length

$\mathrm{W}=$ width of patch

$\mathrm{c}=$ speed of light

$\mathrm{f}_{\mathrm{o}}=$ resonant frequency

$\mathrm{r}=$ relative permittivity

eff $=$ effective permittivity

$\mathrm{L}_{\mathrm{g}}=$ Length of ground plane

$\mathrm{W}_{\mathrm{g}}=$ Width of ground plane $[7-8]$

\section{DESIGN PARAMETERS}

Figure 2(a) and 2(b) shows the front view geometry and the designed structure of the designed microstrip patch antenna with single band operation for the WLAN band on the CST Microwave Studio software. The feed point location and the dimensions for the designed antenna has been optimized so as to get the better possible impedance match to the antenna.

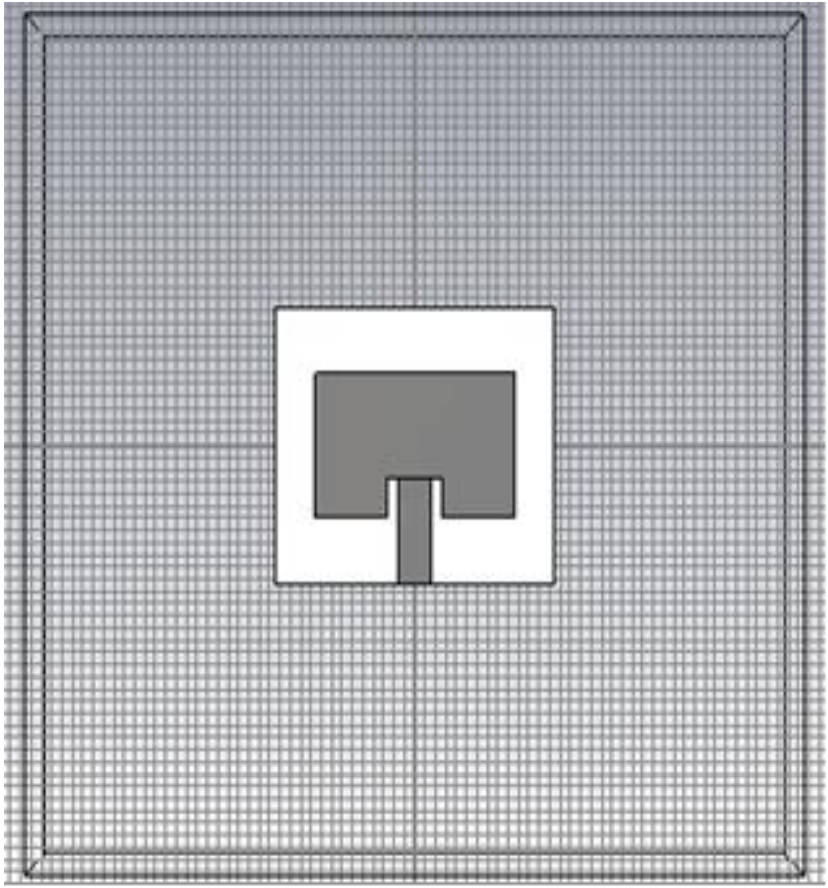

Figure 2(a): Front view geometry of designed antenna

Design frequency $=5.20 \mathrm{GHz}$

Substrate permittivity $=4.4$

Thickness of substrate $=1.524 \mathrm{~mm}$

Length of patch $(\mathrm{L})=11.84 \mathrm{~mm}$

Width of patch $(\mathrm{W})=19.06 \mathrm{~mm}$

Length of Ground $(\mathrm{Lg})=22.64 \mathrm{~mm}$

Width of Ground $(\mathrm{Wg})=26.96 \mathrm{~mm}$

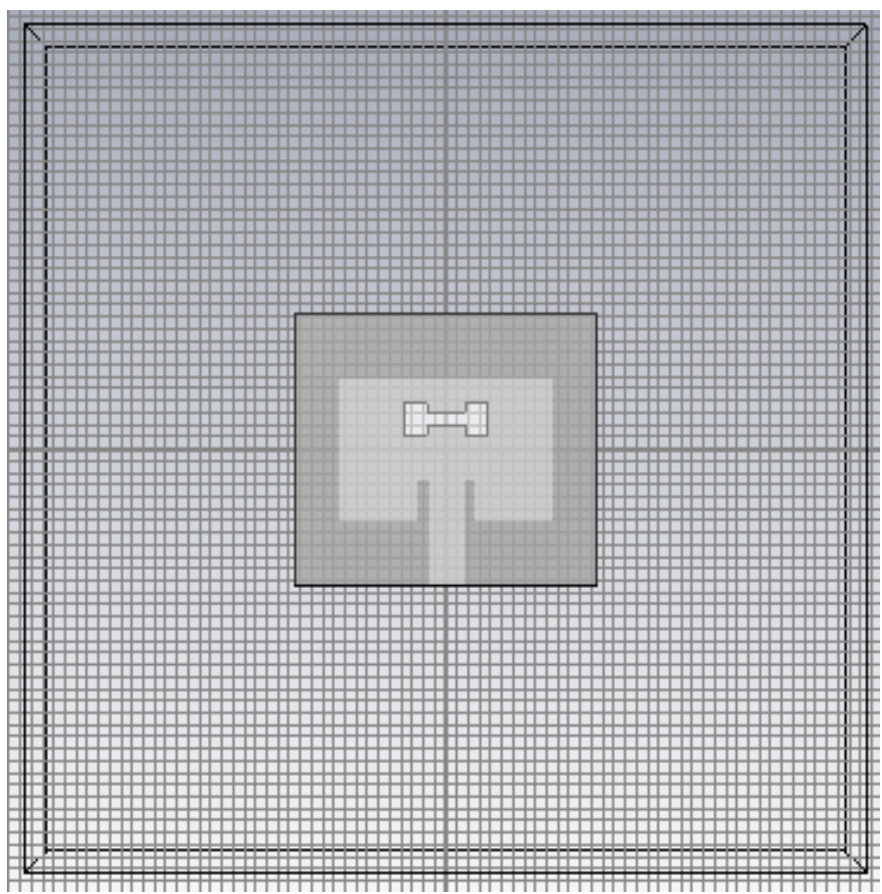

Figure 2(b): Designed structure on CST microwave studio 


\section{STIMULATED RESULTS}

\subsection{Return Loss}

The $S_{11}$ parameter for the proposed antenna was calculated and the simulated return loss results are shown in Figure 3. Return loss is a convenient way to characterize the input and output of the signal sources or when the load is mismatched, not all the available power from generator is delivered to the load. This "loss" is termed as the return loss (RL) [10]. The value of return loss is $-40.302 \mathrm{~dB}$ in this proposed antenna. The achieved return loss value is small enough and frequency is very closed enough to the specified frequency band for 5.2 $\mathrm{GHz}$ WLAN applications. The value of return loss i.e. -40.302 $\mathrm{dB}$ shows that at the frequency point i.e. below the $-10 \mathrm{~dB}$ region there is good matching A negative value of return loss shows that this antenna had not many losses while transmitting the signals [10].

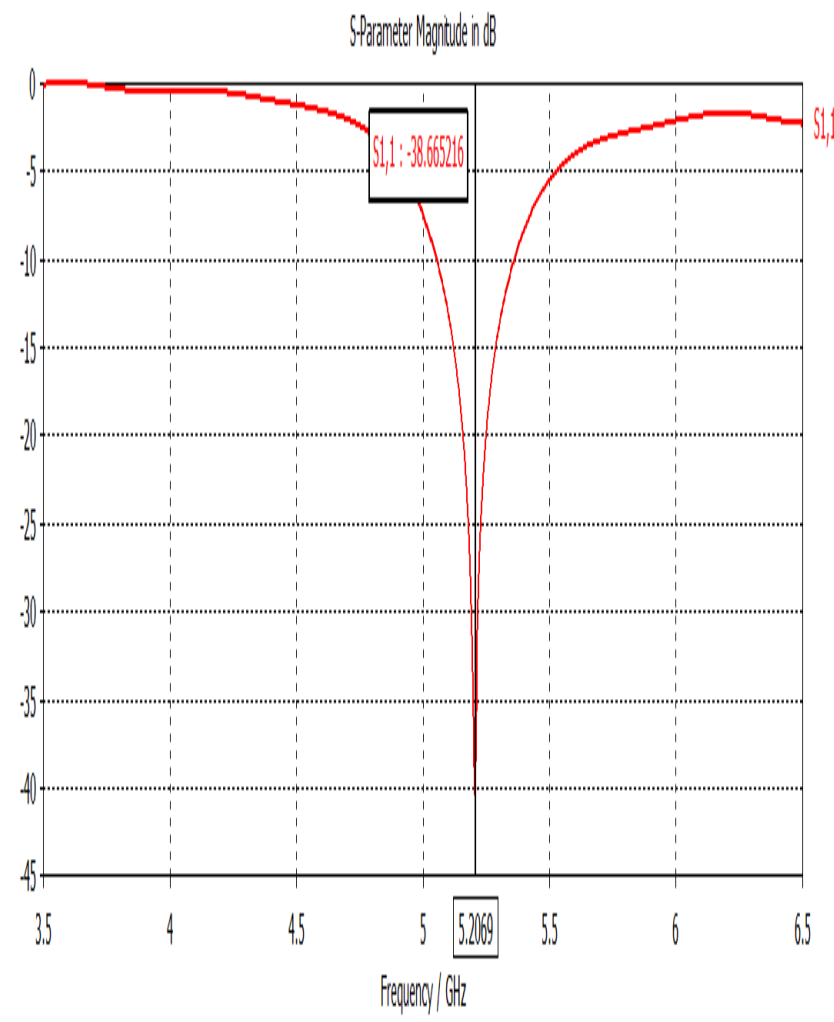

Figure 3: Stimulated return loss curve

\subsection{Bandwidth}

The bandwidth at the resonating frequency of $5.20 \mathrm{GHz}$ is 304 $\mathrm{MHz}$ with corresponding value of the return loss as -40.302 $\mathrm{dB}$ as shown in Figure 4. Several approaches have been used to enhance the bandwidth of the antenna but in this design the bandwidth of $304 \mathrm{MHz}$ is achieved by using Defected Ground Structure. The antenna covers the WLAN application standard IEEE 802.11 (5.2 GHz band).

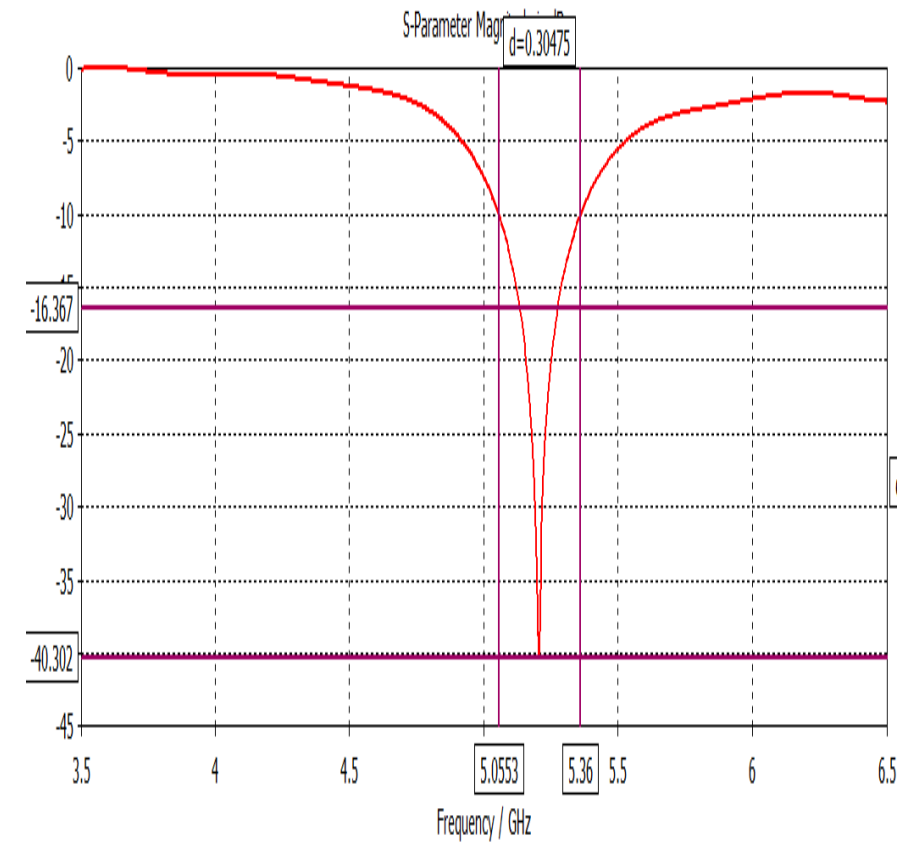

Figure 4: Bandwidth plot

\subsection{Smith Chart and VSWR}

The achieved antenna impedance is $50 \mathrm{ohm}$ as shown in Figure 5, which is the required impedance. VSWR (Voltage Standing Wave Ratio) is a measure of impedance mismatch. The VSWR ratio of proposed antenna is 1:1.023 as shown in Figure 6, which should lie in between 1 and 2 .

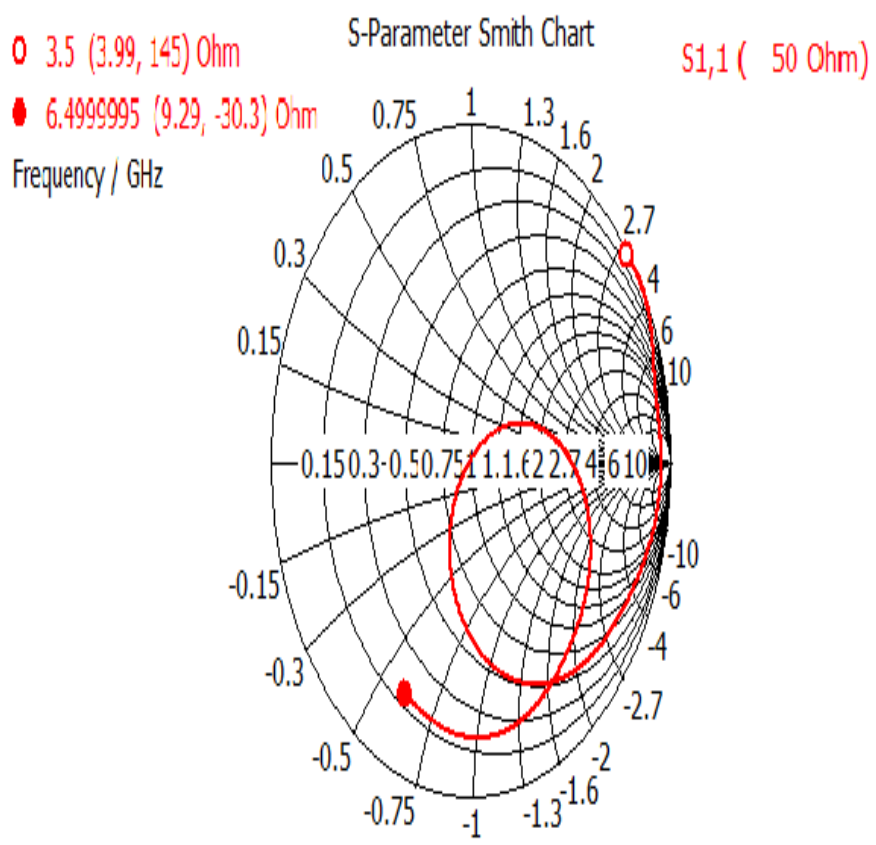

Figure 5: Curve showing antenna characteristic impedance 


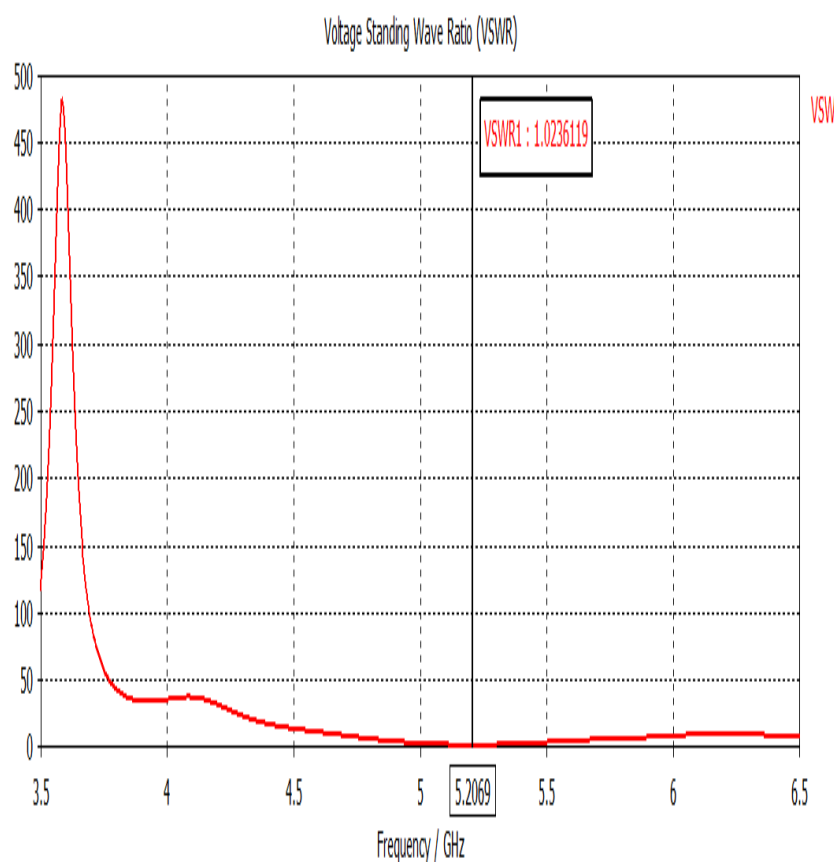

Figure 6: VSWR curve

\subsection{Directivity}

It is desirable to maximize the radiation pattern of the antenna response in a fixed direction in order to transmit or receive power. Likewise, the directivity is dependent only on the shape of the radiation pattern [10]. The achieved directivity of proposed antenna is $6.119 \mathrm{dBi}$ at resonating frequency of 5.20 $\mathrm{GHz}$ as shown in figure 7 . It shows that proposed antenna radiates in omni-directional nature.

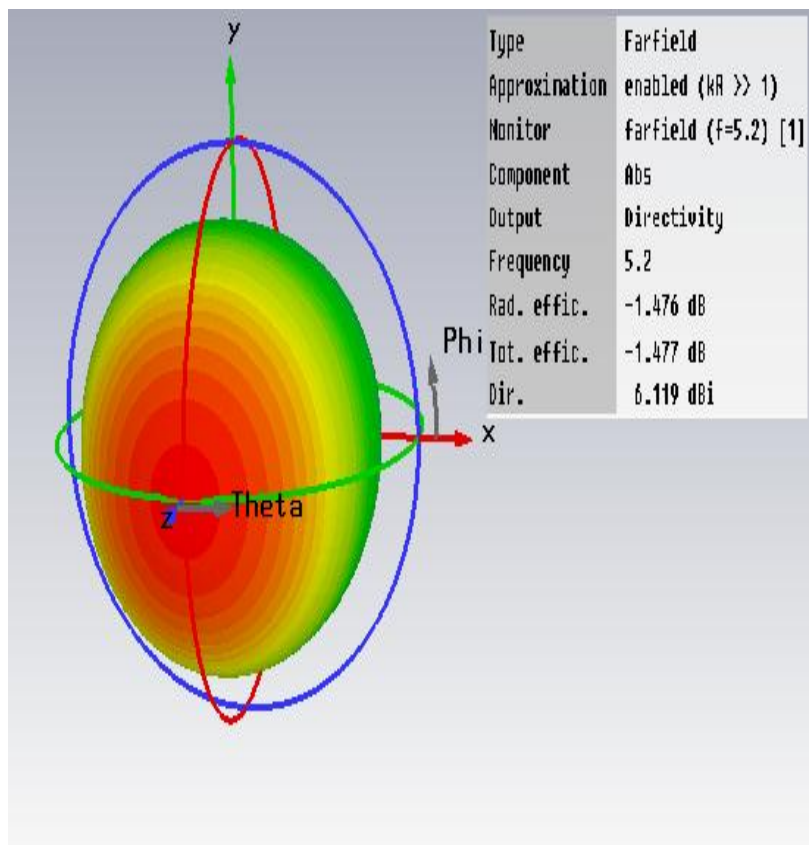

Figure 7: Directivity of designed antenna

\subsection{Gain}

Gain is a very important parameter of every antenna. Basically, the gain is the ratio of the radiated field intensity by test antenna to the radiated field intensity by the reference antenna [9]. Antenna gain, usually expressed in $\mathrm{dB}$, simply refers to the direction of maximum radiation [10]. In this study, the gain of the proposed antenna at frequency of 5.2 $\mathrm{GHz}$ is $4.642 \mathrm{~dB}$ as shown in Figure 8.

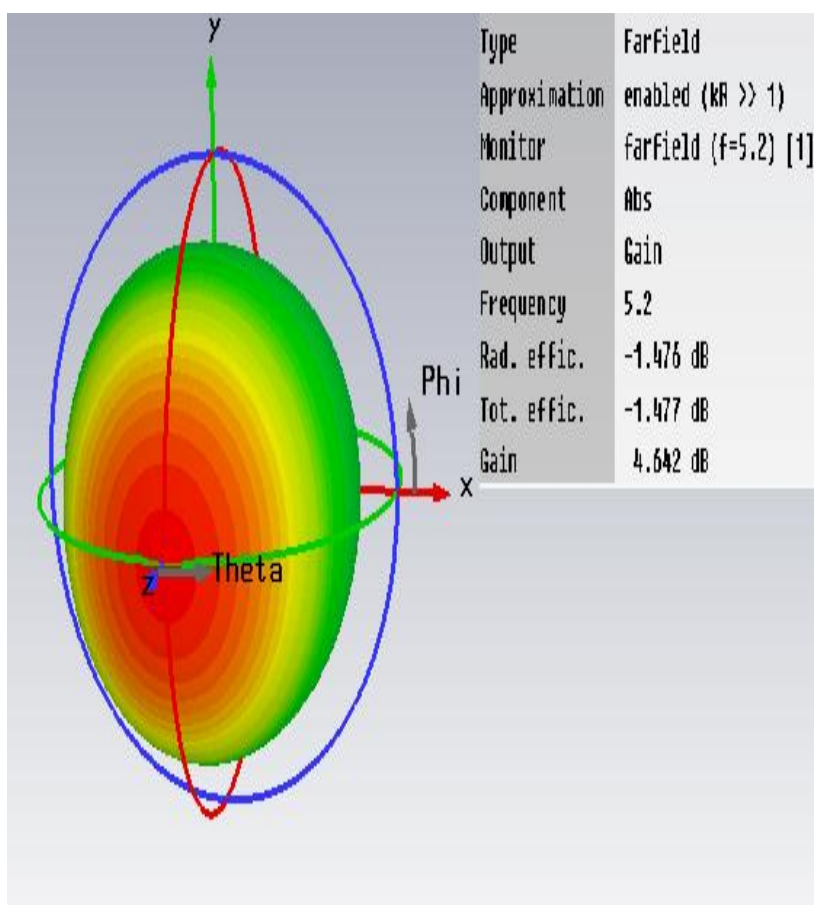

Figure 8: Gain of designed antenna

\section{CONCLUSION}

The designed single band microstrip patch antenna is operating in the frequency band of $5.055 \mathrm{GHz}-5.360 \mathrm{GHz}$ covering $5.2 \mathrm{GHz}$ WLAN communication standard. The resultant bandwidth at $5.2 \mathrm{GHz}$ frequency is around $304 \mathrm{MHz}$ with the corresponding value of return loss $-40.302 \mathrm{~dB}$ which shows that the impedance matching is good at this frequency. The resultant gain of desired antenna is $4.642 \mathrm{~dB}$ which is not so good but it can be increased by using gain enhancement techniques and the directivity of the proposed antenna is 6.119 $\mathrm{dBi}$ which shows that the antenna radiates in omni-directional nature. It has good impedance matching of $50 \mathrm{ohm}$. The resultant bandwidth is good due to defected ground structure but the size of the antenna is not very small. Work is going on to achieve even best results.

\section{ACKNOWLEDGMENTS}

The authors are very thankful to the referees for their valuable comments. 


\section{REFERENCES}

[1] Constantine A Balanis. 2005. Antenna Theory, Analysis and Design. John Wiley \& Sons Inc, 2nd Edition (Reprint).

[2] K. L. Wong. 2003. Compact and Broadband Microstrip Antennas. John Wiley \& Sons.

[3] Rampal Kushwaha, Prof. Kanchan Cecil, "Design and analysis of gain for rectangular microstrip patch antenna using symmetrical cuts", International Journal of Advance Technology \& Engineering Research (IJATER), November 2011.

[4] L. H. Weng, Y. C. Guo, X. W. Shi, and X. Q. Chen. 2008, "An Overview On Defected Ground Structure", Progress In Electromagnetics Research B, Vol. 7, 173189

[5] Rajeshwar Lal Dua, Himanshu Singh, Neha Gambhir, "2.45 GHz Microstrip Patch Antenna with Defected Ground Structure for Bluetooth", International Journal of Soft Computing and Engineering (IJSCE) ISSN: 22312307, January 2012, Volume-1, Issue-6.

[6] Arya, A.K. Kartikeyan, M.V., Patnaik, A, "Efficiency enhancement of microstrip patch antennas with Defected Ground Structure", IEEE proc. Recent Advanced in
Microwave theory and applications (MICROWAVE-08), November 2008, pp.729-731.

[7] Neha ahuja, Rajesh khanna, Jaswinder Kaur, "Design of Single Band Rectangular Patch Antenna for WLAN Application", International Conference on Recent Advances and Future Trends in Information Technology (iRAFIT2012) Proceedings published in International Journal of Computer Applications ${ }^{\circledR}$ (IJCA) pp 29-31.

[8] Neha ahuja, Rajesh khanna, Jaswinder Kaur, "Dual Band Defected Ground Microstrip Patch Antenna for WLAN/WiMax and Satellite Application”, International Journal of Computer Applications (0975 - 8887), June 2012, Volume 48- No.22.

[9] Deepak Sood, Gurpal singh, Chander Charu Tripathi, Suresh Chander Sood, Pawan Joshi, "Design, Fabrication and Characterization of microstrip square patch antenna array for X-band applications", Indian journal of pure and applied Physics, August 2008, Vol. 46, pp. 593-597.

[10] Z. 1. Dafalla, W. T. Y. Kuan, A. M. Abdel Rahman, and S. C. Shudakar, "Design of a Rectangular Microstrip Patch Antenna at $1 \mathrm{GHz}, \mathrm{RF}$ and Microwave Conference, October 5 - 6, 2004, Subang, Selangor, Malaysia. 